Previous Census returns have shown that during the latter years of inter-censal periods grave errors in the estimates of populations of various cities have been made. With regard to Liverpool the error at the close of the last Census amounted to 100,000 persons-about 19 per cent. of the total population-an error great enough to vitiate the -tatistics published by the Registrar-General for several years preceding the Census. As you point out, Dr. Ogle, the late Superintendent of the Statistical Department, addressed a letter in 1885 to the town clerk upon the subject of the estimated population, but unfortunately data were not then available to test the trustworthiness of the estimate. That circumstance, however, can hardly be advanced as an argument for declining to consider evidence now available and which tends to show that the estimate of to-day is incorrect.

The Registrar-General estimates that since 1891 the population of Greater Liverpool has increased from 629,443 to 633,078 , making a total increase of 3635 . The reasons for believing that this estimate is too low may be summarised thus: Since the Census of 1891 the increase in the number of births over deaths amounts to 39,616 , the increase in the number of registered voters amounts to 28,466 , there is an increase of 2376 in the number of houses built over those demolished, and there is an increase in the number of in habited houses of 14,448. This latter figure was ascertained by a careful enumeration by specially instructed constables whose returns were made upon specially prepared forms, and whose results as far as possible were afterwards checked. Local knowledge of the conditions of labour, of the action of the Insanitary Property Committee, together with other matters, must not be left out of sight as available means of checking the correctness of the estimate of the population. Sc far as the birth-rate is concerned, this, it is quite true, in certain listricts in Iiverpool is always high, but a remarkable increase in the birth-rates is exhibited since 1891 in the old parts of the city where the under-estimate of population is believed to be most marked. Excluding the suburbs recently incorporated the birth-rate in the old city (with a population of 497,505) is, upon the Registrar-General's estimate, 37.5, as against an average of 34.9 during ten years ending 1896 . It is wholly improbable that a population with so high a birthrate is diminishing as rapidly as the Registrar-General's estimate indicates.

If the City of Liverpool had not absorbed certain suburbs, the population of the city and those suburbs would have been calculated separately, and by the Registrar-General's method the resulting total would have been 11,051 greater than it is under the Registrar-General's method now adopted by which city and suburbs are calculated as one whole. In other words, extension to the suburbs of municipal government has, in the Registrar-General's opinion, lessened the population by 11,051 . I have been in communication with the medical officers of health of the other great towns with a view to ascertain whether they consider the RegistrarGeneral's published returns as to their own cities are dependable. The medical offlcers of health of 29 out of 31 of the other great towns have favoured me with their replies ; 5 of them consider that the Registrar-General's estimate is fairly correct, 3 are very doubtful and express dissatisfaction with the method, whilst no less than 21 are of the opinion that the method is wholly incorrect and unreliable. No doubt the views of these gentlemen are merely expressions of opinion, but nevertheless their opinions are based upon local knowledge and are entitled to serious consideration. As regards the small towns the most conspicuous instance of error which I know is that of Bootle, the population of which, according to the Registrar-General's estimate, is almost 40 per cent. higher than what those with local knowledge believe it to be ; the local authority have consequently discarded the Registrar-General's method entirely and adopted an estimate of their own.

It may be asked, What does it matter whether the returns are accurate or inaccurate? The importance of the matter is very considerable. There can be no doubt that if during the greater part of the decade ending 1891 the rate of mortality had been correctly published sanitary measures would have been more actively carried into effect. As it was, the decline in the rate of sickness and mortality shown by fictitious returns obscured the need for sanitary measures. Similarly, an under-estimate of population in certain districts masks the results of sanitary measures. Old rookeries are demolished, open spaces provided, artizans" wellings on modern patterns are erected, and, so far as the
Registrar-General's returns are to be taken as an index, the leath-rate of the district is higher than it ever was before. Those who believe that the returns of a Government Department are carefully considered can only conclude that the pent-up rookeries were more wholesome than the new dwellings and that money and labour are spent in vain.

It does appear that there are good grounds for the riew that the published returns of the Registrar-General should either be amended or accompanied by some explanatory note showing that after so long a period from the Census the figures are to be regarded only as approximately correct. I note with satisfaction your powerful adrocacy of a quinquennial census, an adrocacy based on the knowledge that the present returns are umreliable and need amendment.

I am, Sirs, yours faithfully, E. W. HOPE.

Public Health Department, Liverpool, June 22nd, 1898.

\section{ON THE NECESSITY OF A MEDICAL INFIRMARY FOR CHESTERFIELD.}

To the Eatitors of THE LANCET.

SIRs, - The need of a medical infirmary has long been felt and for many years I have advocated its necessity, but hitherto without success. A majority of the governors and subscribers of the present surgical hospital are against admitting medical cases, as it is contrary to its original constitution, and they maintain that its invested money or reserve fund was left for surgical purposes only, as well as the money which was spent in the erection of the present buildings. There is, in my opinion, no probability that this determination will be altered in the present generation and meanwhile the sick poor continue to suffer. I have therefore for many years recommended the erection of a separate infirmary for medical cases. There is a population of 25,000 in the borough of Chesterfield and 120,000 in the district outside without any infirmary except the one at the union, which is almost always full and, indeed, crowded. The infirmaries at Sheffield and Derby are respectively twelve and twenty-four miles distant. I have, I think, made out a strong case for immediate action being taken. I think I am right in stating that there is no district in England with such a large and increasing population without such a charitable provision.

I am, Sirs, yours faithfully, JoHN Rose, M.D. Aberd. Honorary Consulting Surgeon, Chesterfield and Chesterfield, June 22nd, 1898. Consulting Surgeon, Chest
North Derbyshire Hospital.

\section{"THE COMING ELECTION TO THE COUNCIL OF THE ROYAL COLLEGE OF SURGEONS OF ENGLAND."}

To the Editors of THE LANCET.

SIRs,- In view of the approaching election of members to the Council of the Royal College of Surgeons of England I have asked an expression of opinion from the various candidates, and especially from the two provincial ones, who naturally rely on the rotes of the provincial Fellows. It seems certainly strange that, although circulars have been sent out on behalf of the latter gentlemen, no statement of policy or opinion on matters of interest to the Fellows has been made. Why this should be I cannot understand. Every candidate who is to be: elected by the votes of a constituency, such as candidates for Parliament, \&c., always makes some pronouncement as to their policy. Why not candidates for the Council? 1. As to the question whether Members should be admitted to some share in the management of their own Council $\mathrm{Mr}$. May says: "I am opposed to any change in the present mode of election to the Council and the Presidentship." 2. With regard to the question of the Council taking action to check those Members and Fellows who act for medical associations. who allow touting for members he says: "While I strongly disapprove of Fellows and Members holding appointments in which touting for sick members is allowed, and would support any reasonable and legal efforts to check this evil, I cannot promise beforehand to support any particular course of action which is unknown to me."

As to the point as to how the College representative on the General Medical Conncil is to be elected he sass: :" I am not 
in favour of the election of the representative on the General Medical Council by direct vote of the whole body of Fellows and Members. I should be sorry to see this mode of election introduced and cannot promise support in that direction." I may say that Mr. Richardson Cross does not wish me to publish his letters to me about the matter, but I think I may say that he wishes to keep an open mind on these questions and whilst not definitely opposing does not promise to support any of these propositions. As I have been told on good anthority that one more member on the reforming side would at any rate give a majority in favour of the last proposition $I$ think it is a pity some candidate holding these views has not come forward on this occasion. I have mot received any replies up to this date from the other candidates. Trusting you will publish this for the information of the Fellows of the College.

I am, Sirs, yours faithfully,

Portland-villas, Plymouth, June 28th, $1898 . \quad$ G. JACKsON.

\section{THE SALINE TREATMENT OF DYSENTERY.}

To the Editors of THE LANCET.

SIRs, - A recent correspondence in a contemporary shows that the treatment of dysentery by salines (especially sulphate of magnesia) is not as well known as it should be, several writers referring to it as something new. It was, I am informed, first suggested by Bartholow in his "Materia Medica," and for the past eight years it has been much used oy civil surgeons in India, vide Leahy's paper, ${ }^{1}$ Poynder, and Walsh. ${ }^{3}$ In the latter the rational treatment of dysentery is discussed. A reference to Surgeon-Major Leahy's valuable paper will show the advantages he claims for the saline over the ipecacuanha treatment. Salines have also been constantly used for years by French colonial surgeons. In my experience there are three kinds of dysentery met with clinically-viz., mild, acute, and chronic." Anything will cure mild cases provided they get rest in bed and low diet. Acute cases in strong persons react splendidly to ipecacuanha in large doses (from 20 to $25 \mathrm{gr}$.). Other cases are best treated by sulphate of magnesia (saturated solution). The so-called chronic form of dysentery is very different from the above. There is nothing specific about it: it is a low gangrenous form of ulceration which occurs in cachectic cases and is frequently the terminal repisode in such cases. It is found in cases of malarial or tuberculous cachexia, in cases which might be called sprue, in "famine diarrhoea," and among exhausted pilgrims going to and from the shrines of India. Such cases need infinite care and patience and a milk diet. The dysenteric stools alternate with diarrhoea or there are intervals of constipation. This form of alternating dysentery and diarrhcea with periods of quiescence much resemble clinically the so-called "amobic dysentery," with the great difference that they are almost never connected with liver abscess. But nowadays we find few believers in amcobic dysentery (except in America). Even Kartulis, having shown the amoeba coli in healthy stools, is less confident as to the pathogenic rôle of the amcoba. Other more formidable microbes seem to be the active agents. To return to the question of treatment. Rest and sago diet will cure the mild cases in a few days, hence the post hoo success of numerous drugs, the latest of which is cinnamon powder. For acute dysentery in strong, sturdy Europeans or natives I give ipecacuanha in Scott-Doeker's method; in the weakly I prefer saturated solution of Epsom salts (two-drachm doses three or four times a day). For chronic dysentery ipecacuanha is best avoided, and castor-oil, soda, antiseptics, such as salol and bismuth may be tried; in some cases where there is an acute exacerbation use the Fpsom salts, but general treatment and milk diet are above all necessary, and infinite patience. Perchloride of mercury with opium and tinctura nucis romicæ are also useful in chronic cases and often prevent or postpone recurrences. Pages might be written on this subject, but unless we define the class or kind of dysentery met with there is no use in recommending any particular drug. The practical clinical distinction I have made abore will prevent a too great belief

1 Thr LANCET. Oct. 4th, 1890

2 Indian Medical Gazette, July, 189 Ibid., September, 1891.

4 Vide Practitioner, December, 1897. in the powers of a drug which may only lave been tried in mild cases which scarcely need drugs at all.

I am, Sirs, yours faithfully,

W. J. Buchanan, B.A., M.B. Dub.

May 18th 1898

Surgeon-Captain, I.M.S.; Superintendent, Central Gaol, Midnapore.

\section{POISONING BY STRYCHNINE.}

To the Editors of THE LANCET.

SIRs,-Dr. Robert Barnes asks in l'HA LANCET of June 18th, "What will the anti-vivisection bigot's say to this application of experimental science to the aid of justice"? Dr. Thomas Stevenson arrived at the conclusion that death was due to poison partly by physiological tests-i.e., he gave some of the poison to animals. To what animals? Falck says that serpents and fish experience no tetanic phenomena with strychnine and that the frog is really less susceptible to strychnia than various mammals and that it requires four times the dose needed by dogs, cats, rabbits, \&c., to produce an equal effect on frogs. Stillé and Maisch say that birds are comparatively insusceptible to the poison." Ten grains may fail to kill a sheep; cats resist it singularly and guineapigs and monkeys are said to be little affected by it "The anti-rivisection bigots" would have some justification therefore for a little scepticism about the value of the physiological test in poisoning cases. Dr. Barnes says the experimental method teaches us how to treat convulsions. But surely we have all learned the lesson by clinical experience long ago. Why do all the books on poisoning by strychnine insist on the use of anæsthetics to keep the patient perfectly quiet so as to avoid the onset of convulsions if it be necessary to recur to animal experimentation for fresh lessons in treatment?

I am, Sirs, yours faithfully,

EDWARD BERDOE, M.R.C.S., \&C.

Victoria-park-gate, B., June 21st, 1898.

* * Although the dose required by certain animals may be larger the result is ultimately the same. Resistance to poisons differs even in man to some extent.--ED. L

\section{"THE MEDICAL EXPERT AID COMMITTEE."}

To the Editors of THE LANCET.

Sins,-My attention has been drawn to an article appearing in your issue of June 18th, and at the request of the sub-committee of the above $I$ desire to allude to certain matters to which reference therein is made. It is true that at present Dr. Woods is the only medical gentleman on the committee, one reason being that it is not and does not pretend to be anything but a number of ladies and gentlemen who (being well aware of the needs of the class for which it was formed, and of the fact that whenever the services of a medical man are really wanted, no matter whether he be a consultant or a general practitioner, those services are ungrudgingly and generously rendered to the patient, whether such patient can or cannot and regardless whether he will or will not pay the usual fee) desire to secure for such class of persons the services of the consultant, but upon terms that will secure to the consultant some recompense for his advice and at the same time remove the patient from the ranks of the hospital or non-paying patients. It is quite possible that the committee might be strengthened by the addition of medical men, and this matter I can assure you will receive the careful consideration of the committee.

You have alluded in your article to the number of hours a consultant spends in the hospital doing gratuitous work. This committee is well aware of such fact and is firmly convinced that a considerable portion of such time should be spent by such consultant in seeing some of the patients he now sees, but instead of seeing them in the hospital he should see them in his own consulting-room upon the terms that the patients so seen should pay to such consultant fees within their means, for if a patient can afford to pay a modified fee, surely he should pay such modified fee rather than nothing at all to the consultant. The consultant will give the patient the benefit of not a part, but the whole of his skill, learning, and 